\title{
DISASTERS AND THE ELDERLY: THE TURKEY CASE
}

\author{
Timur Gultekin ${ }^{1}$, Nehir Varol ${ }^{2}$ \\ ${ }^{1}$ Ankara University, Faculty of Languages, History and Geography, \\ Department of Physical Anthropology, Ankara, Turkey \\ ${ }^{2}$ Ankara University, Emergency and Disaster Management Department, \\ Ankara, Turkey
}

\begin{abstract}
From the past to the present, people have been exposed to very different kinds of disasters, and it is evident that women, children, the elderly and the disabled are the groups most affected by disasters. As elderly people differ according to their socio-economic, health and psychological status, they can be undefended and vulnerable to many emergencies. Protection of these disadvantaged/vulnerable people from disaster risks, raising their awareness and taking measures for these groups in disaster plans are highly important. The aim of this study is to find what should be done to secure their life and livelihood. Therefore, based on secondary research, this study analyses their current situation, challenges they face during and after disasters. Within the scope of this aim, this study is focused on gaining experience from natural disasters that occurred in Turkey in the past and people's reaction to these disasters, especially their effects on the elderly.
\end{abstract}

Keywords: vulnerable groups in disasters; elderly and disaster; disaster risk management; ageing

\section{INTRODUCTION}

"Old age" is defined in its dictionary meaning as being aged, showing the demeanour of increased age effects [1]. Human aging can be described as a complex of events that interact as a result of the (economic, social) interaction of biological, psychological and environmental factors. In other words, aging actually is a reduction in the human organism's ability to adapt to environmental factors. 
In the past, the proportion of young people and adults in communities was higher than the elderly population, but the increase in life expectancy in today's society has also increased the proportion of elderly people in society. The average life expectancy of Homo habilis, known as the first human who lived about 2.5 million years ago, was $18-20$ years. From 2.5 million years ago to the beginning of the 20th century, life expectancy showed a slight increase [2]. Figure 1 shows the average lifespan of people in historical periods, and Figure 2 shows life expectancy at birth in different countries.

The aging of the population is one of the most important demographic occurrences foregrounded in the 21st century. All over the world, people live longer, birth rates decrease, and, therefore, the elderly population is increasing numerically and proportionally. Aging of population affects all aspects of the society, from health to social security, environmental education, business opportunities, socio-cultural activities and family life [5].

The aging phenomenon, which is more prominent in developed countries, is now gaining importance in developing countries, and the elderly population is increasing in Turkey. The researches done show that Turkey is moving to a new demographic structure. According to the projections of the Turkish Statistical Institute (TUSI), in 2012 the population at 65 years of age and over was 5.7 million; it is estimated that by 2023 it will rise to 8.6 million, by 2050 to 19.5 million and by 2075 to 24.7 million.

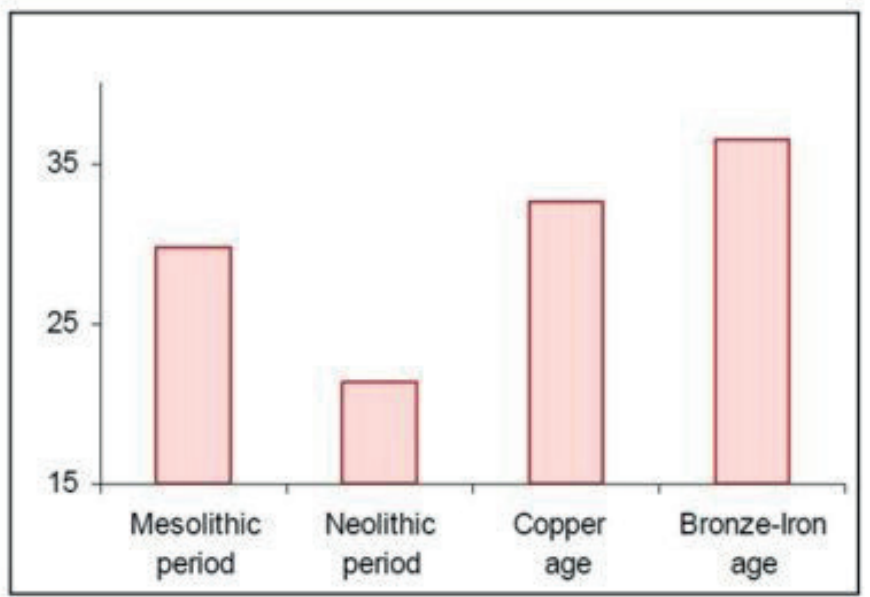

Figure 1. Average lifespan of people in historical periods [3]. 


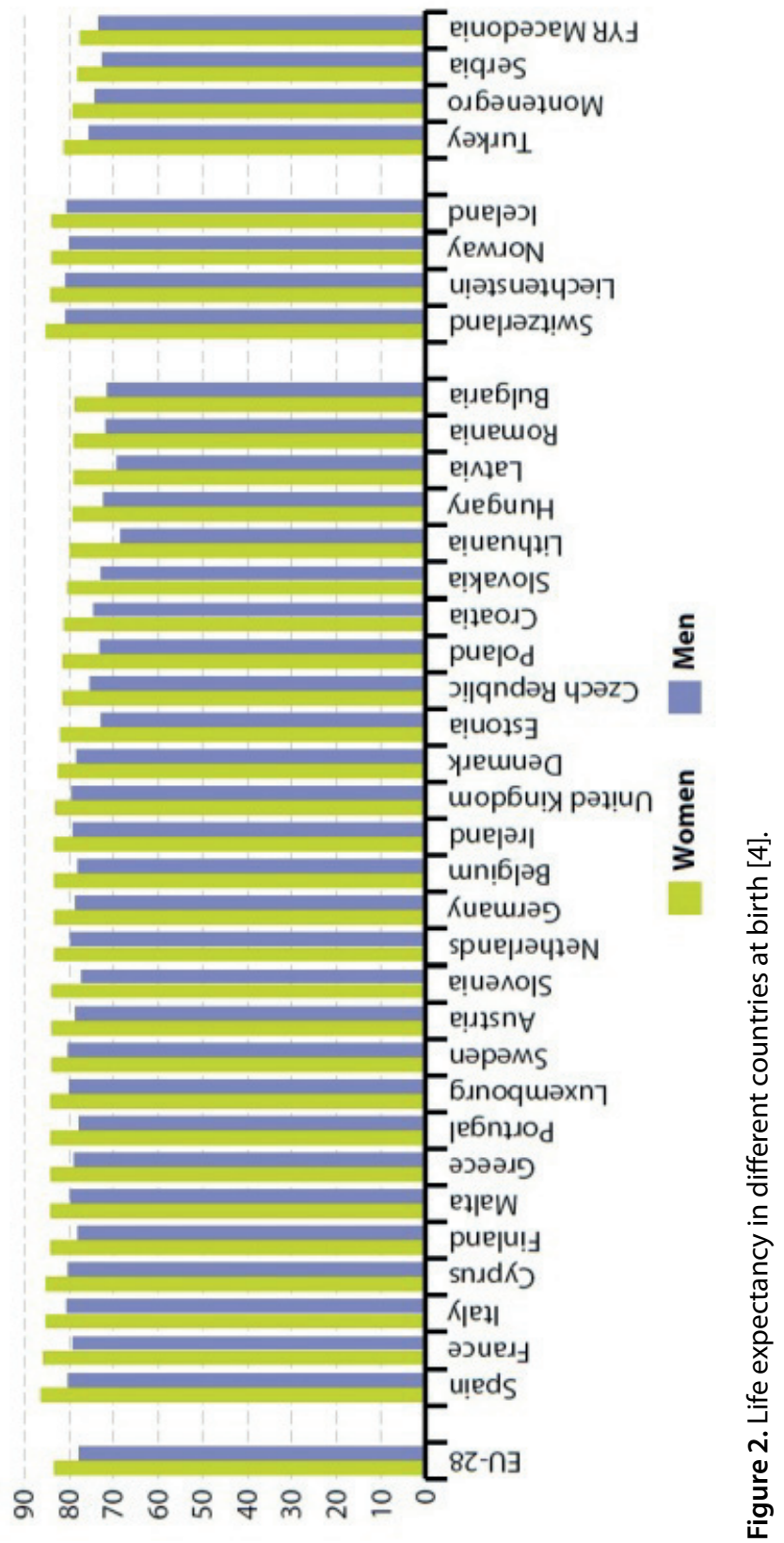


Life span was identified as the most important population change in the 21st century. According to the United Nations Population Fund (UNPF) 2012 report [6], there are now 810 million people over 60 years old worldwide, which is equivalent to $11.5 \%$ of the global population, and it is estimated that this figure will double in 2050 and reach about two billion people. In 2050 there will be 64 countries with elderly population which will make at least $30 \%$ of the general population.

The elderly along with women and children are among the most vulnerable/ injured groups in emergencies and disasters. This vulnerability emerges in different dimensions in the stages of preparation, intervention and remediation of the disaster management system. When designing disaster management systems of countries, it is necessary to consider vulnerable groups in planning. Success in disaster management requires a multidisciplinary approach. Apart from technical, engineering and economical aspects, social, anthropological and cultural dimensions should not be ignored either.

The situation of the elderly in Turkey and in the world, in disasters and emergency situations at every stage and the related regulations and questions of what needs to be done in this issue constitute the subject of this study. The groups more affected by disasters and emergencies are expressed by vulnerable groups, fragile groups, and groups with high vulnerability concepts. In this study, vulnerable group expressions were used.

\section{THE ELDERLY VULNERABLE GROUP IN DISASTERS}

Natural disasters and other emergencies are situations that disrupt daily life, lead people to helplessness, lead to misery, and impair the balance between people and the environment. The elderly are a fragile group who need special care before and after the disaster because they are in the risk group in society. According to the classification of the World Health Organization (WHO), the middle ages between $45-59$ years, old ages between $60-74$ years, older ages between 75-89 years and old age of 90 and over are categorised as old age. Every disaster affects the elderly disproportionately. For this reason, governments and disaster and emergency managers should recognise that elderly people are vulnerable and should develop strategies to meet their needs. "Weak seniors" refers to elderly adults with serious, chronic health problems that may make them more vulnerable during disruptive disasters [7]. 
Why are elderly people regarded as vulnerable in disasters and accidents? Because the majority of the elderly have physical disabilities and most of them have chronic diseases. Many of them live alone and need care. Morphological, physiological, anatomical, mental and spiritual distortions and abrasions can be seen especially in old age, for example, weight loss, muscular weakness due to muscle loss, and slow motion and subsequent decline in physical activity during the day.

Approximately $20-30 \%$ of people over 60 have one or more discomforts physical, mental or sensory. This rate reaches $50 \%$ in people over 80 years old. Surveys show that $20 \%$ of older people have limitations in their ability to do at least one daily activity such as bathing, eating, dressing, toilet, walking or transportation $[8,9]$. Unfortunately, in the event of a disaster or an emergency, there are also problems in transferring, moving or disposing of elderly people from the disaster area. During the catastrophe, many elderly adults cannot be evacuated, most cars are not available, or transportation to public transport is sometimes not possible. After the disaster, public transport services can be suspended for a long time. They also have difficulties in reaching humanitarian aid after disasters. The food aid provided is also sometimes a risk for the elderly. It may not be suitable for people with chronic diseases such as diabetes and tension disorders. For most elderly, food contains too much sodium, fat and calories. After a disaster, chronic diseases can easily worsen due to food and water deficiency, extreme heat or cold, stress and exposure to infection [7, $10,11,12]$.

\section{THE ELDERLY AND THEIR VULNERABILITY IN TURKEY}

Besides its biological properties, human life is social. Along with aging, changes in biological properties as well as social changes are seen. The elderly generally live a sedentary life, passing most of their time at home, depending on the constraints of their ability to move. For this reason, the association of the elderly with their children, grandchildren and other friends in the vicinity is very important in old age. The elderly want to maintain their relations with their family members more intensively and consistently, especially as they get older.

However, it has been observed that the elderly have a reduced working strength; therefore, they stay away from work environment, and close relationship with people generally decreases after the children leave home. It should not be forgotten that a close relationship between family members has a great importance in terms of assistance in disasters. 
When we look at the old age and old age social patterns in Turkey from the historical point of view, in ancient Turkey, it was understood that an ancestor a woman or a man - was always protected. Since the Republican era, there have been rapid and important changes in society and family life in Turkey. Rapid changes have changed social institutions, behaviours and values; changes in the family have affected the status and functions of the elderly. Especially in rural areas, elderly people living with their families enjoy great respect, transferring decision-making, representation of the family, experience and knowledge to younger generations. While the urban and rural family structure is changing in Turkey, the functions of the family have not changed in the same direction. As a result, families are expected to receive mutual help and support among relatives.

In addition to financial assistance, parental assistance is required in child care, while the responsibility for care and livelihood of the elderly parents falls on adult children. It is known that, in recent years, there has been more sensitivity about how nursing homes are arranged, and how old people can be healthy in physical and psychological terms. However, although the physical conditions and economic recovery are achieved, even the most miraculous medicines cannot always keep old people alive. Social support and societal breaks in developed societies have negative implications for the mental health of the elderly; respect, remembrance and adoration of elderly have moved to the background. Social support to developed societies and breaks in social relations have negative implications for the mental health of the elderly. However, it should be emphasized that continuing of family ties in Turkey is important for the soul and body in terms of the elderly.

As a result, the higher levels of desire to live and the desire to connect to life can make the elderly more resilient to the emergency and disaster conditions.

\section{EXAMPLES OF THE SITUATION OF THE ELDERLY IN THE CASE OF DISASTER AND EMERGENCY}

After disasters in many countries, including developed countries, it appears that elderly people are among the most affected groups. In developing and underdeveloped countries this rate is even higher. In New Orleans, more than 70 percent of those killed by Hurricane Katrina have been identified as elderly people. Many of the 200 people who died as a result of the hurricane in Mississippi were also elderly adults. The Louisiana Department of Health reports that most of the elderly people who died were living in nursing homes and 
were abandoned by their caregivers at the time of the disaster. It has also been observed that, after the disaster, more than 200,000 elderly adults with chronic diseases such as diabetes and asthma could not get their medicines and could not access health services [13]. The majority of the 465 people who died of the heat wave in Chicago in 1995 were aged 75 years or older [14].

The tsunami disaster in Indonesia in 2004 also affected mostly the elderly and children. The majority of those who died during the hot air wave that affected Europe in 2003 were again the elderly population. $70 \%$ of people who lost their lives in France were elderly people over 75 years of age. The majority of the deaths in the Kobe earthquake in 1995 and the $90 \%$ of the deaths in the later period constituted elderly people.

In order to make an assessment of the post-disaster situations of the elderly, HelpAge International has interviewed 300 elderly women and men aged 60 years and over living in cities and camps in Lebanon, South Sudan, and Ukraine in 2015. During the interviews, the elderly said that the related institutions did not reach them for the difficulties they were exposed to in the case of disasters and emergencies; they were being disinterested in, and their ideas were not considered. Some indicated that there was no information about disasters and what needed to be done in the event of a disaster. Some said that sufficient humanitarian assistance had not reached them, and some had failed to reach health services. Half of the interviewed people said they felt worried and hopeless [15].

As we can see, those who live in disasters or after disasters are an important risk source for elderly penetration. Above, attempts have been made to give examples of how the elderly individuals may suffer disproportionately in disasters. But it is important to remember the relations between the family and young individuals and the status of elderly individuals in emergencies. Young individuals see elders as reliable leaders in general, and they form a basis for experience, action and even material and spiritual respect.

\section{STUDIES TO BE PERFORMED ABOUT HOW THE ELDERLY CAN COPE WITH DISASTERS AND EMERGENCY SITUATIONS}

In disasters, $80 \%$ of the elderly in general can be exposed to any chronic condition. This leads to the need to pay more attention to them than to healthy people. We can regard these chronic conditions as changes that are experienced as part of physiological, sensory, and cognitive aging. As a result, elderly people need special attention and care in emergency situations and disasters 
[16]. From this point of view, who can help the elderly in emergency situations and disasters and how can they help? In this regard, the question how to create professional teams should be dealt with.

First, the areas where the elderly live in large numbers and the professionals who can support this area need to be identified. Also, information on disasters and measures against disasters should be made public, and everyone should have a plan against disaster risks.

Old age often does not create fragility alone. However, advanced age can create vulnerability when combined with physical weakness and chronic illnesses, poverty and loneliness. According to the data of the Centres for Disease Control and Prevention, more than half of the elderly adults have some functional limitations [17]. Therefore, the severity of the effects of emergencies and disasters on older people is related to the relationship of the elderly to the environment, the type and severity of the disaster, the disaster management system model and the interaction between all of them [17].

A number of measures can be taken considering that older people, who are vulnerable in disasters and emergency situations, are more likely to be affected during and after the disaster. Some of these measures can be summarised as follows:

- State agencies should encourage individuals and families to make an emergency plan.

- To encourage governments and practitioners to make preparations and rescue plans for the elderly, social services by specialist counsellors should be given to the elderly for the events they will be facing.

- Teams for the elderly in emergency and disaster should be established. These teams need to be trained because older people may have different needs and capabilities.

- Ergonomic living spaces should be created for the elderly, and the need for emergency accommodation should be resolved quickly.

- Measures should be taken for the elderly at home and outside the home, plans made for the elderly in urban transformation projects.

- The elderly should be encouraged to exercise to live a healthy, active and independent life.

- By taking advantage of the experience of healthy elderly people, a volunteer team can be established, and with the help of this team disaster and emergency situations can be interfered. This team can be private or can be created with government support. 
- In general, it is important to ensure that elderly people are able to access the early warning system in the case of disasters and emergencies, taking into consideration the difficulties in moving and the decrease in vision and hearing functions.

- The evacuation system in old care homes should be planned as soon as possible.

- Information systems should be developed that can support research related to aging, including statistical data on places and situations where elderly people live.

- Annual exercises should be conducted to determine the effectiveness level of the plan for the elderly.

- Needs of the elderly people exposed to disasters should be determined; information about chronic diseases and obstacles should be obtained and humanitarian aid should be provided to the elderly.

- Psychological counselling services should be provided to the aged after disasters.

- Age-sensitive plans must be made. Social assistance services should be provided for isolated people who cannot access services. When providing humanitarian aid, it is necessary to carry out a comprehensive needs analysis based on gender, age and disability.

- During before-disaster and emergency planning studies, the addresses of the elderly should be determined and added to the plans by using the Geographic Information System. Thus, in disasters and emergencies, the places where the elderly live can be reached without losing time.

- In the case of an emergency, the elderly need to have water, ready-to-eat food, a hand-held flashlight and radio, and batteries for them.

- In the case of an emergency, first the situation must be assessed, planning for shelter and location selection. The main issues are adequate nutrition, clean water supply and sanitation, contagious disease and epidemic control, provision of coordinated emergency medical services [5].

\section{CONCLUSIONS}

Sociological, anthropological and cultural approaches must be taken into account in the creation and implementation of disaster management systems, including their technical dimensions [18]. All disaster risk management policies, plans, decision-making processes and training activities should be made considering individual differences. Equal access to nutrition, shelter, medical 
intervention and other services for the elderly during and after disasters and emergencies will only be possible with such risk mitigation efforts. In order to optimize all of these, it is necessary for both voluntary and government organisations to exchange information in advance and profoundly analyse their capacities in action against disasters.

\section{REFERENCES}

1. Duyar İ. (2008). Yaşlanma, yaşl1lı ve antropoloji. In: Mas M.R., Işık T., Karan M.A., Beğer T., Akman Ş., Ünal T., eds. Geriatri. 1st ed. TGV, 9-19.

2. Akın G. (2006). Her yönüyle yaşlılık. 1st ed. Palme Yayıncılık.

3. Galor O., Moav O. (2007). The neolithic revolution and contemporary variations in life expectancy. SSRN, 14. https://doi.org/10.2139/ssrn.1012650.

4. Eurostat Statistics Explained (2012). Population structure and ageing. Available at http://ec.europa.eu/eurostat/statistics-explained/index.php/Sustainable_development_-_public_health Accessed March 1, 2018.

5. National Plan for Ageing of Turkey (2007). Türkiyede yaşlıların durumu ve yaşlanma ulusal eylem planı. Sosyal Sektörler ve Koordinasyon Genel Müdürlüğü, DPT Yayınları, No:2741.

6. United Nations Population Fund (2012). UNFPA annual report. https://www. unfpa.org/sites/default/files/pub-pdf/AR\%202012\%20EN-Final.pdf Accessed March 1, 2018.

7. Fernández-Ballesteros R. (2002). Social support and quality of life among older people in Spain. Journal of Social Issues, 58, 4, 645-659. https://doi.org/10.1111/1540-4560.00282

8. Schmid K., Vézina S., Ebbeson L. (2008). Disability in the Caribbean: A study of four countries: a socio-demographic analysis of the disabled. United Nations Publications.

9. Merck Institute of Ageing and Health (2004). The state of aging and health in Latin America and the Caribbean. http://www.civicengagement.org/agingsociety/pdf/LACreport.pdf Accessed March 1, 2018.

10. Bierman A.S. (2001). Functional status: the sixth vital sign. Journal of General Internal Medicine, 16, 11, 785-786. https://doi.org/10.1111/j.1525-1497.2001.10918.x

11. Menotti A., Mulder I., Nissinen A., et al. (2001). Prevalence of morbidity and multimorbidity in elderly male populations and their impact on 10-year allcause mortality: The FINE study (Finland, Italy, Netherlands, Elderly). Journal of Clinical Epidemiology, 54, 7, 680-686.

https://doi.org/10.1016/S0895-4356(00)00368-1 
12. Mudur G. (2005). Aid agencies ignored special needs of elderly people after tsunami. BMJ: British Medical Journal, 331, 7514, 422. https://doi.org/10.1136/bmj.331.7514.422

13. The White House (2006). The federal response to Hurricane Katrina: lessons learned. https://georgewbush-whitehouse.archives.gov/reports/katrina-lessonslearned/ Accessed March 1, 2018.

14. International Longevity Center-USA (2006). Ageism in America. Available at http://aging.columbia.edu/sites/default/files/Ageism_in_America.pdf Accessed March 1, 2018.

15. Age International. Older voices in humanitarian crises: Calling for change. (2016). HelpAge International. https://www.ageinternational.org.uk/Documents/Older\%20voices\%20in\%20humanitarian\%20crises\%20-\%20Report.pdf Accessed March 1, 2018.

16. Aldrich N., Benson W.F. (2008). Disaster preparedness and the chronic disease needs of vulnerable older adults. Prev Chronic Dis, 5, 1.

17. CDCP, Centers for Disease Control and Prevention. Morbidity and mortality weekly report (Rapid assessment of the needs and health status of older adults after Hurricane Charley--Charlotte, DeSoto, and Hardee Counties, Florida, August 27-31, 2004). Available at http://www.cdc.gov/mmwr/preview/ mmwrhtml/mm5336a2.htm Accessed March 1, 2018.

18. Varol N., Gültekin T. (2016). Afet antropolojisi. Elektronik Sosyal Bilimler Dergisi, 15, 59, 1431-1436. https://doi.org/10.17755/esosder.263244 [In Turkish, English abstract]

\section{Address for correspondence:}

Nehir Varol

Ankara University

Emergency and Disaster Management Dept.

06730 Beypazar1-Ankara, Turkey

E-mail: nehir.varol@ankara.edu.tr 